\title{
Acute Kidney Injury in Neonates: From Urine Output to New Biomarkers
}

\author{
Alexandre Braga Libório, ${ }^{1,2}$ Klébia Magalhães Pereira Castello Branco, ${ }^{2}$ \\ and Candice Torres de Melo Bezerra ${ }^{1}$ \\ ${ }^{1}$ Public Health Postgraduate Program, Universidade de Fortaleza, UNIFOR, Fortaleza, CE, Brazil \\ ${ }^{2}$ Internal Medicine Department, Faculdade de Medicina, Universidade Federal do Ceará, Avenida Abolição No. 4043, \\ Ap. 1203 Edifício Jangada, Mucuripe, 60165-082 Fortaleza, CE, Brazil
}

Correspondence should be addressed to Alexandre Braga Libório; alexandreliborio@yahoo.com.br

Received 28 November 2013; Accepted 23 December 2013; Published 5 March 2014

Academic Editor: Vecihi Batuman

Copyright (c) 2014 Alexandre Braga Libório et al. This is an open access article distributed under the Creative Commons Attribution License, which permits unrestricted use, distribution, and reproduction in any medium, provided the original work is properly cited.

\begin{abstract}
In the past 10 years, great effort has been made to define and classify a common syndrome previously known as acute renal failure and now renamed "acute kidney injury (AKI)." Initially suggested and validated in adult populations, AKI classification was adapted to the pediatric population and recently has been modified for the neonatal population. Several studies have been performed in adults and older children using this consensus definition, leading to improvement in the knowledge of AKI incidence and epidemiology. In spite of these advances, the peculiar renal pathophysiology of critically ill newborn patients makes it difficult to interpret urine output (UO) and serum creatinine (SCr) levels in these patients to diagnose AKI. Also, new urine biomarkers have emerged as a possible alternative to diagnose early AKI in the neonatal population. In this review, we describe recent advances in neonatal AKI epidemiology, discuss difficulties in diagnosing AKI in newborns, and show recent advances in new AKI biomarkers and possible long-term consequences after AKI episode.
\end{abstract}

\section{Introduction}

Acute kidney injury (AKI), previously known as acute renal failure, is defined by an acute and reversible increment in serum creatinine (SCr) levels associated or not with a reduction in urine output (UO) oliguria/anuria. It is a complex disorder with clinical manifestations ranging from mild injury to complete kidney failure, generally requiring renal replacement therapy, peritoneal dialysis or hemodialysis. Evidence shows that it is not just a marker of illness severity in the pediatric or adult patients but that it has a direct association with poor outcomes $[1,2]$.

The epidemiology of AKI has changed in the past few decades, with rapid advances in medical technology. Recent studies recognize that even small increments in serum creatinine (SCr) levels increase morbidity and mortality $[3,4]$. Moreover, it has been clearly demonstrated that AKI has implications in long-term outcomes in adults and children, compromising survival and increasing chronic kidney disease incidence [5].
The prevalence of in-hospital AKI is high and the incidence of AKI secondary to another systemic illness or another treatment is now higher than that of primary renal disease [6]. Due to different definitions, it was difficult to determine AKI real incidence, especially in children. Recently, new definition and classification [7] have renewed the interest in this topic and new studies in older children and neonatal population are being performed. Furthermore, the advances in new biomarkers that enhance clinical diagnosis capacity and the implementation of possible early treatment have promoted the study of AKI in children. Despite these advances and new technologies in renal replacement therapies, the mortality rate from AKI remains elevated and, at least in the adult population, has remained stable over the past 50 years [8].

In newborns patients, AKI importance and dilemmas are even more pronounced, as a newborn's kidneys are more susceptible to hypoperfusion and have low glomerular filtration rate, high renal vascular resistance, high plasma renin activity, decreased intercortical perfusion, and decreased reabsorption of sodium in the proximal tubules. All these 
TABLE 1: Comparison between AKI classification system in adults, older children, and newborns.

\begin{tabular}{|c|c|c|c|c|c|}
\hline & \multicolumn{2}{|c|}{ Creatinine criteria } & \multicolumn{3}{|c|}{ Urine output criteria } \\
\hline & RIFLE & pRIFLE and nRIFLE & RIFLE & pRIFLE & nRIFLE \\
\hline Risk & $\begin{array}{l}\text { Increased creatinine } \mathrm{x} 1.5 \text { or } \\
\text { GFR decreases }>25 \%\end{array}$ & $\begin{array}{l}\text { Increased creatinine } \mathrm{x} 1.5 \text { or } \\
\text { GFR decreases }>25 \%\end{array}$ & $\begin{aligned} \mathrm{UO} \leq & 0.5 \mathrm{~mL} / \mathrm{kg} / \mathrm{h} \\
& \times 6 \mathrm{~h}\end{aligned}$ & $\begin{array}{c}\mathrm{UO} \leq 0.5 \mathrm{~mL} / \mathrm{kg} / \mathrm{h} \\
\times 8 \mathrm{~h}\end{array}$ & $\begin{array}{c}\mathrm{UO}<1.5 \mathrm{~mL} / \mathrm{kg} / \mathrm{h} \\
\quad \text { for } 24 \mathrm{~h}\end{array}$ \\
\hline Injury & $\begin{array}{l}\text { Increased creatinine } \mathrm{x} 2 \text { or } \\
\text { GFR decreases }>50 \%\end{array}$ & $\begin{array}{l}\text { Increased creatinine } \mathrm{x} 2 \text { or } \\
\text { GFR decreases }>50 \%\end{array}$ & $\begin{aligned} \mathrm{UO} \leq & 0.5 \mathrm{~mL} / \mathrm{kg} / \mathrm{h} \\
& \times 12 \mathrm{~h}\end{aligned}$ & $\begin{aligned} \mathrm{UO} \leq & 0.5 \mathrm{~mL} / \mathrm{kg} / \mathrm{h} \\
& \times 16 \mathrm{~h}\end{aligned}$ & $\begin{array}{l}\mathrm{UO}<1.0 \mathrm{~mL} / \mathrm{kg} / \mathrm{h} \\
\quad \text { for } 24 \mathrm{~h}\end{array}$ \\
\hline Failure & $\begin{array}{l}\text { Increased creatinine } \mathrm{x} 3 \text { or } \\
\text { GFR decreases }>75 \% \text { or } \\
\text { creatinine }>4 \mathrm{mg} / \mathrm{dL} \text { (acute } \\
\text { rise of }>4 \mathrm{mg} / \mathrm{dL} \text { ) }\end{array}$ & $\begin{array}{l}\text { Increased creatinine } \mathrm{x} 3 \text { or } \\
\text { GFR decreases }>75 \% \text { or } \\
\text { GFR }<35 \mathrm{~mL} / \mathrm{min} / 1.73 \mathrm{~m}^{2}\end{array}$ & $\begin{array}{c}\mathrm{UO} \leq 0.3 \mathrm{~mL} / \mathrm{kg} / \mathrm{h} \\
\times 24 \mathrm{~h} \text { or anuria } \times \\
12 \mathrm{~h}\end{array}$ & $\begin{array}{c}\mathrm{UO} \leq 0.3 \mathrm{~mL} / \mathrm{kg} / \mathrm{h} \\
\times 24 \mathrm{~h} \text { or anuria } \times \\
12 \mathrm{~h}\end{array}$ & $\begin{array}{c}\mathrm{UO}<0.7 \mathrm{~mL} / \mathrm{kg} / \mathrm{h} \\
\text { for } 24 \mathrm{~h} \text { or anuria } \\
\text { for } 12 \mathrm{~h}\end{array}$ \\
\hline
\end{tabular}

features make newborns more susceptible to injury in the first days of life. Moreover, difficulties in SCr interpretation (discussed below) make it more difficult to achieve a consensus regarding AKI definition. Because of all these difficulties in diagnosing $\mathrm{AKI}$ in newborns, the new biomarkers are expected to be of greater importance in AKI approach in high-risk neonatal populations.

\section{Acute Kidney Injury Definition}

Until recently, AKI definition was broad, which made it difficult to establish comparisons between different studies. Different definitions can be responsible for the difficulties in discerning its real epidemiology and prognosis implications. In 2004, the Acute Dialysis Quality Initiative (ADQI) proposed an AKI classification system called "Risk, Injury, Failure, Loss, End-Stage Kidney Disease (RIFLE)” criteria to promote a consistent and consensus AKI definition [9]. The RIFLE criteria remained to be based on routinely used parameters: acute changes in serum creatinine and reduced urine output (UO)-Table 1. Many studies in different populations, comprising more than 500,000 patients, have validated these criteria in adult populations, correlating AKI severity with early and late mortality, length of hospital stay, and other outcomes [10].

Three years later, RIFLE criteria were modified to be used in children, thus giving rise to the pediatric RIFLE criteria or pRIFLE [7]. The authors adapted glomerular filtration rate (GFR) decline criteria from adults and maintained the same urine output (UO) definition-see Table 1. The main difference is a lower cutoff SCr to achieve the F category, requiring a GFR lower than $35 \mathrm{~mL} / \mathrm{min}$ instead of a SCr of $4.0 \mathrm{mg} / \mathrm{dL}$. Several studies have also validated pRIFLE in children, mainly in critically ill patients or after cardiac surgery [11-16]. After that, it was mathematically demonstrated that it is not necessary to calculate the GFR and that, by using only the SCr increment, it was possible to diagnose and to assess AKI severity [17]. Also, the Acute Kidney Injury Network (AKIN) revised AKI classification and has adopted the percentage SCr increment to diagnose AKI, recognizing that eGFR was not necessary. This is important because it made it possible to diagnose AKI in retrospective studies, in which the researchers often do not have access to children's length, which is necessary to calculate eGFR. Both the AKIN and pRIFLE definitions have been used in several pediatric studies and have been shown to be similar when compared in critically ill and noncritically ill children [17].

Few studies have evaluated pRIFLE or the similar AKIN criteria [18] specifically in neonates $[19,20]$ and none has applied UO criterion in this population. Considering major differences in the neonatal population, mainly in preterm infants (immature tubular cells, higher total body water, and maternal SCr influence), it is difficult to accept all pRIFLE definitions for the neonatal population. A recent study by our group [21] proposed the evaluation of urine output and its impact on outcomes in a critically ill neonatal population. Urine output cutoffs higher than $1.5 \mathrm{~mL} / \mathrm{Kg} / 24 \mathrm{~h}$ were associated with higher mortality, mechanical ventilation duration, and length of hospital stay. These urine output criteria were incorporated to pRIFLE and named neonatal RIFLE, or nRIFLE [22]. Table 1 discloses a comparison between adult, pediatric, and neonatal RIFLE.

Although some studies have recently applied pRIFLE criteria in neonatal populations, mainly in those undergoing cardiac surgery, no other study has included UO criterion and this is a subject that needs further validation. Using UO as a biomarker of neonatal AKI can be especially important due to difficulties in evaluating SCr at this population, as explained below. Finally, the importance of these definitions is highlighted by the need to clarify AKI epidemiology, direct our research efforts, and ultimately improve prognosis.

\section{Epidemiology}

While many studies have emerged in recent years on AKI epidemiology in older children, only a few have evaluated its incidence and clinical importance in newborn patients. Moreover, recent studies with modern AKI definition included only special neonatal populations: postneonatal asphyxia [20], low birth weight [23], and after cardiac surgery [24]. Data on AKI epidemiology in a general neonatal ICU has been scarcely studied [21].

Critically ill neonates are at greater risk of having AKI as they are commonly exposed to nephrotoxic medications and have frequent infections, which leads to multiorgan failure [25]. Older studies estimated that AKI incidence in this population was between 8 and 24\% [26] and a recent study, using UO criterion in addition to $\mathrm{SCr}$, disclosed an incidence of almost $20 \%$ [21]. The importance of different definitions 
of AKI is highlighted by comparison with another new study that used only SCr, where AKI was identified in only $6.3 \%$ of newborn patients [27].

Another neonatal population at especially high risk of having AKI is that with postneonatal asphyxia. The incidence of asphyxia is estimated at between 1 and 10 per 1,000 live births and these patients are prone to multiorgan dysfunction and a redistribution of cardiac output to maintain cerebral, cardiac, and adrenal perfusion, while potentially leading to renal ischemia. Because of the different definitions, AKI incidence postneonatal asphyxia is reported in up to $30 \%$ to $56 \%$ of cases [28-31]. Newborns with AKI after postneonatal asphyxia have an ominous prognosis, particularly those with oliguric AKI [32].

AKI incidence in newborns with congenital heart disease undergoing cardiopulmonary bypass has been assessed in several studies. In a recent prospective multicenter study using pRIFLE criteria [19], AKI occurred in $64 \%$ of the neonates, with $55 \%$ in stage $1,20 \%$ in stage 2 , and $25 \%$ in stage 3. Hospital stay, ICU stay, and mechanical ventilation were longer in those newborns with AKI. Also, in-hospital mortality rate was greater, particularly in those with AKI stage 3 and those requiring dialysis. Interestingly, newborns with advanced AKI (stages 2 or 3 ) had lower height after a two-year follow-up even after adjustment to other variables, demonstrating that AKI has long-term implications, as discussed below.

Two recent studies investigated AKI incidence in low birth weight newborns. Koralkar et al. [23] performed a study in very low birth weight infants $(<1.500 \mathrm{~g})$ and demonstrated that $18 \%$ of the VLBW infants developed AKI and these had a mortality rate 2.4 times greater than the others. In one case-control study in VLBW infants [33], high mean airway pressure, low blood pressure, and the use of cefotaxime were associated with AKI. Finally, in a multicenter study, neonates on extracorporeal membrane oxygenation (ECMO) had an AKI incidence greater than $80 \%$ and AKI was associated with an adjusted mortality rate that was 3.2 times higher [34].

\section{Difficulties to Define Acute Kidney Injury in Neonatal Period}

Despite these functional classification systems, the diagnosis of AKI is troublesome, as current diagnosis is based on two main findings: changes in $\mathrm{SCr}$ and urine output. As in the adult population, both are late effects of injury and not markers of the injury itself and, moreover, neonatal physiology complicates the interpretation of these biological markers [35].

Some important points need to be considered with any neonatal AKI definition and diagnosis. It is generally believed that neonates have nonoliguric AKI [26], but this can be a misconception due to the lack of knowledge about normal UO in critically ill newborns. The total body water content is greater in newborns than in adult patients. Especially in preterm infants, the total body water can be as high as $80 \%$ of body weight [36]. This difference in water content, in addition to immature tubular development, can explain why UO in newborns is normally greater than in other populations. So, it was demonstrated that urine output less than $0.5 \mathrm{~mL} / \mathrm{kg}$ per hour is an nonsensitive marker of AKI and this level must be increased to up to $1.5 \mathrm{~mL} / \mathrm{Kg}$ per hour [21]. This urine output level can be even higher in preterm newborns, because of immature tubular development. In our study, we identified that diuresis as high as $1.5-2.0 \mathrm{~mL} / \mathrm{kg} / \mathrm{h}$ is associated with a fatal outcome in LBW infants.

Serum creatinine is the most practical and often used method to monitor glomerular filtration rate, but its use in the neonatal period is associated with some limitations. During the first $48-72 \mathrm{~h}$ of life, neonatal SCr still reflects maternal levels and these values may decline at varying rates over days, depending on gestational age [26]. Thereby, the levels of SCr during the first week after birth and its changes (or lack of change) may be difficult to interpret. Moreover, SCr concentrations may not change until $25-50 \%$ of the kidney function has already been lost and, at lower GFR, SCr will overestimate renal function due to tubular secretion of creatinine.

Other additional factors need to be recalled: normal nephrogenesis begins at 8 weeks of gestation and continues until the 34th week. Thereafter, GFR improves steadily over the first few months of life. Depending on the degree of the neonate's prematurity, GFR steadily improves during the first week of life, concomitantly with alterations in renal blood flow. Overall GFR in term and preterm infants is very low, and there is a very wide distribution of normal SCr values, which vary greatly, depending on the level of prematurity and age [31].

\section{New Biomarkers in Neonatal Acute Kidney Injury}

Because the incidence of AKI is still high and the outcome remains poor, research has focused on identifying new biomarkers able to anticipate the AKI diagnosis in hours or even days before a UO reduction or SCr increment can be detected. Early AKI diagnosis would bring out new perspectives in therapeutic possibilities. Moreover, the knowledge of novel serum and urine biomarkers may change the approach to AKI and can help to differentiate between different causes of established AKI and implementing preventive interventions. Studies on AKI biomarkers in neonates are limited and mainly performed in specific populations at risk for AKI, such as VLBW, asphyxiated newborns, and children who undergo cardiac surgery with cardiopulmonary bypass $(\mathrm{CPB})$. Studies on biomarkers predicting AKI in general in critically ill neonates are lacking.

There are many challenges in validating AKI biomarkers. Large-scale observational multicenter studies in different critically ill populations and healthy neonates are needed to characterize the differences between the course of SCr and biomarkers during the length of AKI. Also, validation of new biomarkers in clinical practice and testing of markers as predictive factors for endpoints, such as LOS, needed for renal replacement therapy, mechanical ventilation time, and mortality are necessary. 
TABLE 2: Biomarkers in neonatal acute kidney injury.

\begin{tabular}{|c|c|c|c|c|c|}
\hline Author & Study design & AKI definition & Population & Biomarkers & Main findings \\
\hline $\begin{array}{l}\text { Askenazi } \\
\text { et al. [43] }\end{array}$ & $\begin{array}{l}\text { Nested } \\
\text { case-control }\end{array}$ & AKIN & $\begin{array}{l}\text { Very low birth } \\
\text { weight infants } \\
(n=30, \mathrm{AKI}=9)\end{array}$ & $\begin{array}{l}\text { Urine NGAL and } \\
\text { OPN }\end{array}$ & $\begin{array}{l}\text { Urine biomarkers } \\
\text { were higher in those } \\
\text { with AKI. No } \\
\text { information about } \\
\text { early AKI diagnosis. }\end{array}$ \\
\hline $\begin{array}{l}\text { Krawczeski } \\
\text { et al. [44] }\end{array}$ & $\begin{array}{l}\text { Prospective } \\
\text { cohort }\end{array}$ & AKIN & $\begin{array}{l}374 \text { infants }(35 \\
\text { neonates, } \mathrm{AKI}=8) \\
\text { undergoing cardiac } \\
\text { surgery with CPB }\end{array}$ & $\begin{array}{l}\text { Serum and urine } \\
\text { NGAL }\end{array}$ & $\begin{array}{l}\text { Serum and urine } \\
\text { NGAL } 2 \mathrm{~h} \text { after CPB } \\
\text { are early predictive } \\
\text { biomarkers for AKI. }\end{array}$ \\
\hline $\begin{array}{l}\text { Askenazi } \\
\text { et al. [37] }\end{array}$ & $\begin{array}{l}\text { Nested } \\
\text { case-control }\end{array}$ & $\begin{array}{l}\mathrm{SCr} \geq 1.7 \mathrm{mg} / \mathrm{dL} \\
>72 \mathrm{~h} \text { after birth } \\
\text { or rising values } \\
>0.3 \mathrm{mg} / \mathrm{dL} \\
\text { within } 48 \mathrm{~h} \\
(\mathrm{AKIN})\end{array}$ & $\begin{array}{l}\text { Neonates birth } \\
\text { weight }>2000 \mathrm{~g}, \\
\text { GA }>34 \text { weeks, } \\
5 \text {-minute score } \\
\text { Apgar } \leq 7 \\
(n=58,9 \text { neonates } \\
\text { developed AKI) } \\
\end{array}$ & $\begin{array}{l}\text { Urine NGAL, } \\
\text { OPN, uCysc, } \\
\text { albumin, } \beta 2 \\
\text { microglobulin, } \\
\text { epithelial growth } \\
\text { factor, UMOD, and } \\
\text { KIM-1 }\end{array}$ & $\begin{array}{l}\text { Urine CysC, UMOD, } \\
\text { and epithelial growth } \\
\text { factor were higher in } \\
\text { those with AKI. No } \\
\text { information about } \\
\text { early AKI diagnosis. }\end{array}$ \\
\hline Li et al. [45] & $\begin{array}{l}\text { Prospective } \\
\text { cohort }\end{array}$ & $\begin{array}{l}\mathrm{SCr}>1.5 \mathrm{mg} / \mathrm{dL} \text { or } \\
\text { pRIFLE }\end{array}$ & $\begin{array}{l}\text { Nonseptic critically } \\
\text { ill neonates } \\
(n=62, \mathrm{AKI}=11)\end{array}$ & uCysC and uIL-18 & $\begin{array}{l}\text { Urine CysC and IL-18 } \\
\text { are predictive of AKI } \\
\text { in nonseptic critically } \\
\text { ill neonates. }\end{array}$ \\
\hline $\begin{array}{l}\text { Sarafidis et al. } \\
{[46]}\end{array}$ & $\begin{array}{l}\text { Prospective } \\
\text { cohort }\end{array}$ & $\begin{array}{l}\mathrm{SCr} \geq 1.5 \mathrm{mg} / \mathrm{dL} \\
>24 \mathrm{~h} \text { or rising } \\
\text { values }>0.3 \mathrm{mg} / \mathrm{dL} \\
\text { from DOL } 1\end{array}$ & $\begin{array}{l}13 \text { asphyxiated } \\
\text { neonates and } 22 \\
\text { nonasphyxiated } \\
(n=35, \text { AKI }=8)\end{array}$ & $\begin{array}{l}\text { Serum CysC and } \\
\text { NGAL } \\
\text { Urine CysC, } \\
\text { NGAL, and KIM -1 }\end{array}$ & $\begin{array}{l}\text { Serum NGAL and } \\
\text { uNGAL and uCysC } \\
\text { are higher in } \\
\text { asphyxiated neonates, } \\
\text { even in those not } \\
\text { developing AKI. They } \\
\text { had also provided an } \\
\text { early AKI diagnosis. }\end{array}$ \\
\hline $\begin{array}{l}\text { Elmas et al. } \\
\text { [47] }\end{array}$ & Case-control & $\begin{array}{l}\text { pRIFLE or SCr } \\
\geq 1.5 \mathrm{mg} / \mathrm{dL} \text { on the } \\
\text { first } 3 \text { days }\end{array}$ & $\begin{array}{l}\text { Preterm neonates } \\
\text { with RDS }(n=28, \\
\text { AKI }=8) . \\
\text { Additional control } \\
\text { group with } 34 \\
\text { neonates without } \\
\text { RDS nor AKI }\end{array}$ & Serum CysC & $\begin{array}{l}\text { Serum CysC is an } \\
\text { independent } \\
\text { predictor of AKI in } \\
\text { RDS neonates. }\end{array}$ \\
\hline
\end{tabular}

CPB: cardiopulmonary bypass; RDS: respiratory discomfort syndrome; CysC: serum cystatin C; sNGAL: serum neutrophil gelatinase-associated lipocalin; uCysC: urine CysC; uNGal: urine NGAL; KIM-1: kidney injury molecule-1; OPN: osteopontin; B2mG: beta-2 microglobulin; IL-18: interleukin-18; DOL 1: day of life; GA: gestational age; UMOD: uromodulin; PA: postmenstrual age; CPB: cardiopulmonary bypass; RDS: respiratory distress syndrome.

One of the main difficulties is that the new candidate biomarkers are generally tested against $\mathrm{SCr}$, with all the above mentioned problems when used as a gold marker of AKI. Moreover, just like SCr, several studies have shown that some urinary biomarker concentrations depend on gestational age and birth weight $[37,38]$. The inability of immature tubules to reabsorb these proteins is underdeveloped in preterm infants and can lead to different values in this population. In recent studies, the most promising early noninvasive AKI biomarkers were serum cystatin $\mathrm{C}$ (CysC), urinary interleukin-18 (IL-18), serum and urinary neutrophil gelatinase-associated lipocalin (N-GAL), kidney molecule-1 (KIM-1), osteopontin (OPN), and beta-2 microglobulin (B2mG)-Table 2 [39]. Another recent and promising biomarker is angiotensinogen [40]. Urinary angiotensinogen and its association with renin have been associated with severe AKI and need of renal replacement therapy [41, 42]; however, studies focusing on neonatal AKI are lacking. Generally, renal biomarkers are abnormally expressed protein in renal injury that can reflect lesion in several nephron sites and do not necessarily reflect a GFR reduction-Figure 1.

Cystatin C (CysC) is a cysteine proteinase inhibitor expressed in all nucleated cells produced at a constant rate and cleared exclusively by the kidney. Apparently, CysC does not cross the placenta [48] and, thus, reflects the renal function of the neonates in early postnatal life regardless of body composition and size [49]. Serum CysC (sCysC) was measured in 62 preterm neonates with respiratory distress syndrome (RDS) and 34 control neonates without RDS and sCysC was identified as an earlier marker of AKI in preterm neonates with RDS, increasing before SCr [47]. The urinary CysC (uCysC) was also predictive of AKI, in nonseptic critically ill newborns [45]. In another small study, enrolling only 13 asphyxiated newborns, $\mathrm{uCysC}$ was a sensitive and early AKI biomarker. Although other studies have evaluated CystC in older children, it is difficult to extend their results 


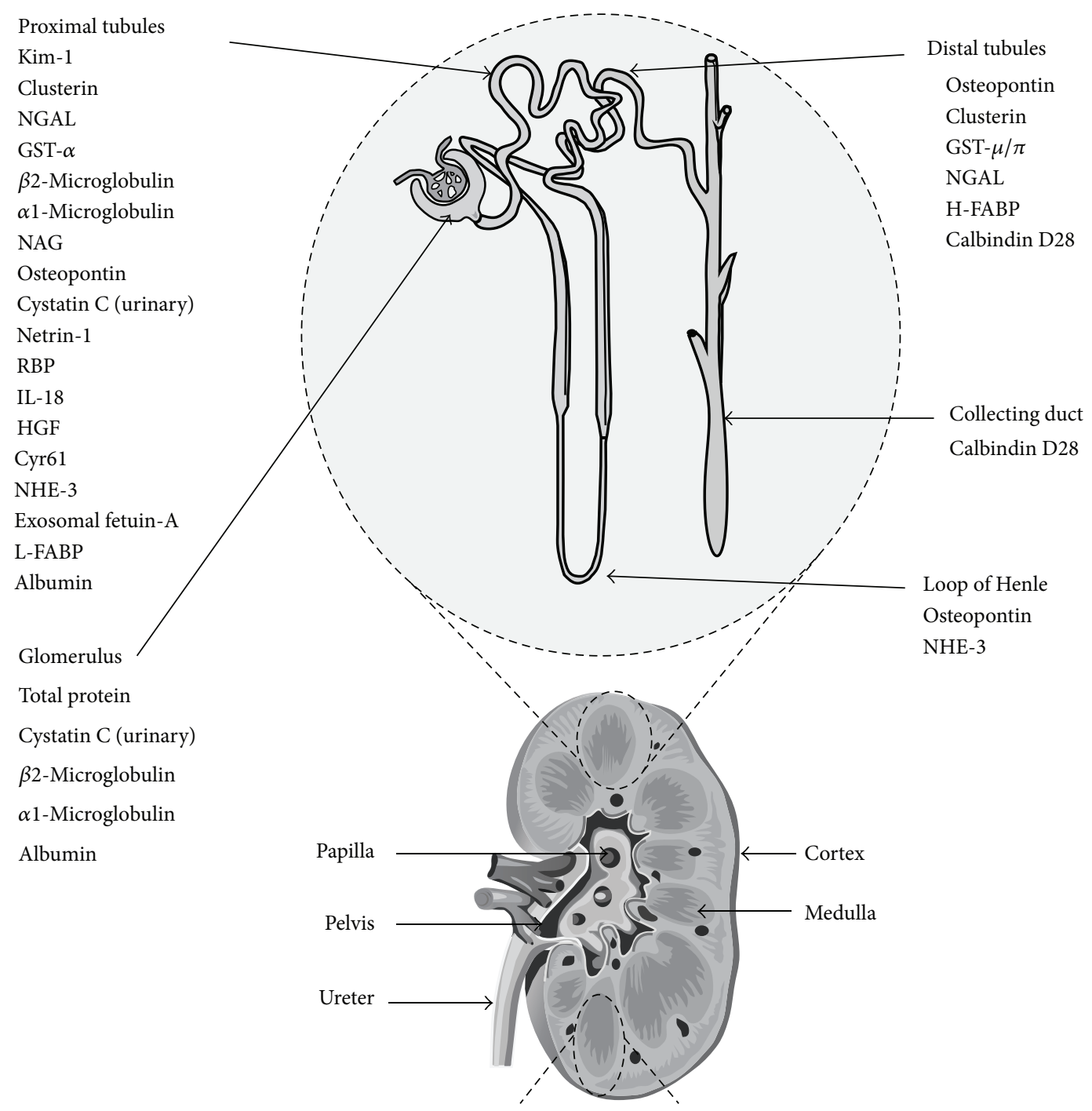

FIgURE 1: Nephron segment-specific biomarkers of kidney injury. Adapted from [40] with permission.

to the neonatal population, considering that normal values of $\mathrm{uCys} C$ decrease with tubular maturation.

Interleukin-18 (IL-18) is a proinflammatory cytokine that is cleaved by caspase- 1 and is released in the proximal tubule after AKI [50]. Li et al. [45] enrolled 62 nonseptic critically ill neonates and urine was collected every $48-72 \mathrm{~h}$ during the first 10 days of life. They demonstrated that both urinary concentration of CysC (cited above) and IL-18 were associated with AKI, even after controlling for gestational and postnatal age, birth weight, gender, Apgar score, and neonatal acute physiology in nonseptic critically ill neonates. Apparently, uIL-18 has a potential advantage of not changing its normal value with increasing renal maturity but can be influenced by sepsis, reducing its ability to detect AKI.

In the only study evaluating OPN in neonatal population [43], a nested case-control study with 30 patients (only 9 with AKI) showed that AKI newborns had greater OPN values than controls. Prospective studies are lacking to ascertain OPN value in predicting neonatal AKI. Furthermore, we could not identify any study evaluating the role of KIM-1 specifically in a neonatal population.

Urinary NGAL appears to be the most promising AKI biomarker and it is the most strikingly upregulated gene and overexpressed protein in the kidney after ischemia [51]. Many studies have evaluated urinary and serum NGAL capacity to predict AKI in both adults $[52,53]$ and older children $[54,55]$. Specifically in the neonatal population, serum and urine NGAL were evaluated in patients after $\mathrm{CPB}$ surgery [44]. Plasma and serum NGAL collected 2 hours after CPB were able to predict AKI with a sensitivity and specificity of nearly $90 \%$. Another study evaluated UNGAL at day 1 in preterm infants and after full adjustment for other factors; it remained significantly associated with AKI development [56].

Another approach to improve AKI diagnosis is to combine multiple biomarkers. Askenazi et al. [43] evaluated 8 candidates for urinary biomarkers: NGAL, IL-18, KIM-1, $\mathrm{OPN}, \mathrm{B} 2 \mathrm{mG}$, and CysC. They explored the individual and 
combined abilities of these biomarkers to predict AKI and mortality in VLBW infants and showed that the combination of three biomarkers was not better than their isolated use; however, this study was only a nested case-control type. Improving our ability to diagnose AKI, maybe with the concomitant use of multiple markers, will allow the implementation of more effective preventive and therapeutic measures to improve AKI prognosis. Finally, some studies have included newborns and older children when evaluating AKI biomarkers [57]. This can lead to erroneous interpretations, as cutoff values can be different even in those patients with different gestational ages and birth weights.

\section{Long-Term Consequences of Neonatal AKI}

Acute kidney injury has been long thought of as a completely reversible syndrome. However, over the past several years, a plethora of data from experimental animal and human studies have been published, indicating that AKI more than likely results in permanent kidney damage (i.e., chronic kidney disease-CKD) and may also result in damage to nonrenal organs [58-60]. Moreover, mortality is higher in adults surviving an AKI episode [61].

In children, it is already known that there is a considerable risk of long-term renal sequelae associated with AKI caused by intrinsic kidney disease, such as Henoch-Schonlein purpura or hemolytic uremic syndrome $[62,63]$. However, longterm renal prognosis of AKI in children without primary renal disease was only recently studied. In a prospective cohort study, 126 children were followed for up to three years after AKI episode [5]. Overall, 10\% of patients developed CKD and the prevalence had a direct correlation with AKI severity, affecting $17 \%$ of patients with AKI stage 3 . In this cohort, only 30 patients had neonatal AKI and 5 (16.6\%) developed CKD, suggesting that this population is of higher risk at developing CKD after AKI episode. In the only study, evaluating AKI long-term sequelae in newborn population, height was reduced in those with AKI after a two-year follow-up [19]. Studies evaluating CKD after AKI episode, specifically in newborn patients, are lacking.

\section{Conclusions}

Acute kidney injury is a syndrome with severe early and long-term consequences. Recent advances in definition and classifications may improve epidemiologic and clinical studies in the pediatric population, including newborns. New biomarkers are important for an early diagnosis and can have a prominent importance in neonatal population, in which UO can be increased by immature tubules and SCr can suffer maternal influence.

\section{Disclosure}

Alexandre Braga Libório is recipient of a grant from the Conselho Nacional de Desenvolvimento Científico e Tecnológico (CNPq). The funders had no role in study design, data collection and analysis, decision to publish, or preparation of the paper.

\section{Conflict of Interests}

The authors declare that there is no conflict of interests regarding the publication of this paper.

\section{References}

[1] K. Singbartl and J. A. Kellum, "AKI in the ICU: definition, epidemiology, risk stratification, and outcomes," Kidney International, vol. 81, no. 9, pp. 819-825, 2012.

[2] E. D. Siew and S. M. Deger, "Recent advances in acute kidney injury epidemiology," Current Opinion in Nephrology and Hypertension, vol. 21, no. 3, pp. 309-317, 2012.

[3] M. Zappitelli, P. L. Bernier, R. S. Saczkowski et al., "A small postoperative rise in serum creatinine predicts acute kidney injury in children undergoing cardiac surgery," Kidney International, vol. 76, no. 8, pp. 885-892, 2009.

[4] O. Alkandari, K. A. Eddington, A. Hyder et al., "Acute kidney injury is an independent risk factor for pediatric intensive care unit mortality, longer length of stay and prolonged mechanical ventilation in critically ill children: a two-center retrospective cohort study," Critical Care, vol. 15, no. 3, article R146, 2011.

[5] C. Mammen, A. Al Abbas, P. Skippen et al., "Long-term risk of $\mathrm{CKD}$ in children surviving episodes of acute kidney injury in the intensive care unit: a prospective cohort study," The American Journal of Kidney Diseases, vol. 59, no. 4, pp. 523-530, 2012.

[6] S. Hui-Stickle, E. D. Brewer, and S. L. Goldstein, "Pediatric ARF epidemiology at a tertiary care center from 1999 to 2001," The American Journal of Kidney Diseases, vol. 45, no. 1, pp. 96-101, 2005.

[7] A. Akcan-Arikan, M. Zappitelli, L. L. Loftis, K. K. Washburn, L. S. Jefferson, and S. L. Goldstein, "Modified RIFLE criteria in critically ill children with acute kidney injury," Kidney International, vol. 71, no. 10, pp. 1028-1035, 2007.

[8] C. R. Lenihan, M. E. Montez-Rath, C. T. M. Mangano, G. M. Chertow, and W. C. Winkelmayer, "Trends in acute kidney injury, associated use of dialysis, and mortality after cardiac surgery, 1999 to 2008," Annals of Thoracic Surgery, vol. 95, no. 1, pp. 20-28, 2013.

[9] R. Bellomo, C. Ronco, J. A. Kellum, R. L. Mehta, and P. Palevsky, "Acute renal failure-definition, outcome measures, animal models, fluid therapy and information technology needs: the second international consensus conference of the acute dialysis quality initiative (ADQI) group," Critical Care, vol. 8, no. 4, pp. R204-R212, 2004.

[10] Z. Ricci, D. N. Cruz, and C. Ronco, "Classification and staging of acute kidney injury: beyond the RIFLE and AKIN criteria," Nature Reviews Nephrology, vol. 7, no. 4, pp. 201-208, 2011.

[11] A. B. Libório, N. A. Rocha, M. J. Oliveira et al., "Acute kidney injury in children with visceral leishmaniasis," Pediatric Infectious Disease Journal, vol. 31, no. 5, pp. 451-454, 2012.

[12] N. Bresolin, A. P. Bianchini, and C. A. Haas, "Pediatric acute kidney injury assessed by pRIFLE as a prognostic factor in the intensive care unit," Pediatric Nephrology, vol. 28, no. 3, pp. 485492, 2013.

[13] Z. Ricci, M. Di Nardo, C. Iacoella, R. Netto, S. Picca, and P. Cogo, "Pediatric RIFLE for acute kidney injury diagnosis and 
prognosis for children undergoing cardiac surgery: a singlecenter prospective observational study," Pediatric Cardiology, vol. 34, no. 6, pp. 1404-1408, 2013.

[14] Y. A. Soler, M. Nieves-Plaza, M. Prieto, R. García-De Jesús, and M. Suárez-Rivera, "Pediatric risk, injury, failure, loss, end-stage renal disease score identifies acute kidney injury and predicts mortality in critically ill children: a prospective study," Pediatric Critical Care Medicine, vol. 14, no. 4, pp. e189-e195, 2013.

[15] T. Palmieri, A. Lavrentieva, and D. Greenhalgh, "An assessment of acute kidney injury with modified RIFLE criteria in pediatric patients with severe burns," Intensive Care Medicine, vol. 35, no. 12, pp. 2125-2129, 2009.

[16] F. B. Plötz, A. B. Bouma, J. A. E. van Wijk, M. C. J. Kneyber, and A. Bökenkamp, "Pediatric acute kidney injury in the ICU: an independent evaluation of pRIFLE criteria," Intensive Care Medicine, vol. 34, no. 9, pp. 1713-1717, 2008.

[17] Z. B. Ozçakar, F. Yalçinkaya, B. Altas et al., "Application of the new classification criteria of the acute kidney injury network: a pilot study in a pediatric population," Pediatric Nephrology, vol. 24, no. 7, pp. 1379-1384, 2009.

[18] B. A. Molitoris, A. Levin, D. G. Warnock et al., "Improving outcomes of acute kidney injury: report of an initiative," Nature Clinical Practice Nephrology, vol. 3, no. 8, pp. 439-442, 2007.

[19] C. J. Morgan, M. Zappitelli, C. M. Robertson et al., "Risk factors for and outcomes of acute kidney injury in neonates undergoing complex cardiac surgery," Journal of Pediatrics, vol. 162, no. 1, pp. 120.el-127.e1, 2013.

[20] D. T. Selewski, B. K. Jordan, D. J. Askenazi, R. E. Dechert, and S. Sarkar, "Acute kidney injury in asphyxiated newborns treated with therapeutic hypothermia," Journal of Pediatrics, vol. 162, no. 4, pp. 725.el-729.el, 2013.

[21] C. T. Bezerra, L. C. Vaz Cunha, and A. B. Libório, "Defining reduced urine output in neonatal ICU: importance for mortality and acute kidney injury classification," Nephrology Dialysis Transplantation, vol. 28, no. 4, pp. 901-909, 2013.

[22] Z. Ricci and C. Ronco, "Neonatal RIFLE," Nephrology Dialysis Transplantation, vol. 28, no. 9, pp. 2211-2214, 2013.

[23] R. Koralkar, N. Ambalavanan, E. B. Levitan, G. McGwin, S. Goldstein, and D. Askenazi, "Acute kidney injury reduces survival in very low birth weight infants," Pediatric Research, vol. 69, no. 4, pp. 354-358, 2011.

[24] A. Alabbas, A. Campbell, P. Skippen, D. Human, D. Matsell, and C. Mammen, "Epidemiology of cardiac surgery-associated acute kidney injury in neonates: a retrospective study," Pediatric Nephrology, vol. 28, no. 7, pp. 1127-1134, 2013.

[25] S. P. Andreoli, "Acute renal failure in the newborn," Seminars in Perinatology, vol. 28, no. 2, pp. 112-123, 2004.

[26] J. G. Jetton and D. J. Askenazi, "Update on acute kidney injury in the neonate," Current Opinion in Pediatrics, vol. 24, no. 2, pp. 191-196, 2012.

[27] P. Vachvanichsanong, E. McNeil, S. Dissaneevate, P. Dissaneewate, P. Chanvitan, and W. Janjindamai, "Neonatal acute kidney injury in a tertiary center in a developing country," Nephrology Dialysis Transplantation, vol. 27, no. 3, pp. 973-977, 2012.

[28] M. E. Norman and F. K. Asadi, "A prospective study of acute renal failure in the newborn infant," Pediatrics, vol. 63, no. 3 , pp. 475-479, 1979.

[29] R. L. Chevalier, F. Campbell, and A. N. A. G. Brenbridge, "Prognostic factors in neonatal acute renal failure," Pediatrics, vol. 74, no. 2, pp. 265-272, 1984.
[30] B. D. Gupta, P. Sharma, J. Bagla, M. Parakh, and J. P. Soni, "Renal failure in asphyxiated neonates," Indian Pediatrics, vol. 42, no. 9, pp. 928-934, 2005.

[31] A. Aggarwal, P. Kumar, G. Chowdhary, S. Majumdar, and A. Narang, "Evaluation of renal functions in asphyxiated newborns," Journal of Tropical Pediatrics, vol. 51, no. 5, pp. 295-299, 2005.

[32] A. M. Durkan and R. T. Alexander, "Acute kidney injury post neonatal asphyxia," Journal of Pediatrics, vol. 158, no. 2, pp. e29e33, 2011.

[33] S. Iacobelli, S. Loprieno, F. Bonsante, G. Latorre, L. Esposito, and J. B. Gouyon, "Renal function in early childhood in very low birthweight infants," The American Journal of Perinatology, vol. 24, no. 10, pp. 587-592, 2007.

[34] D. J. Askenazi, N. Ambalavanan, K. Hamilton et al., "Acute kidney injury and renal replacement therapy independently predict mortality in neonatal and pediatric noncardiac patients on extracorporeal membrane oxygenation," Pediatric Critical Care Medicine, vol. 12, no. 1, pp. el-e6, 2011.

[35] D. J. Askenazi, N. Ambalavanan, and S. L. Goldstein, "Acute kidney injury in critically ill newborns: what do we know? What do we need to learn?" Pediatric Nephrology, vol. 24, no. 2, pp. 265-274, 2009.

[36] G. Hartnoll, P. Bétrémieux, and N. Modi, "Body water content of extremely preterm infants at birth," Archives of Disease in Childhood: Fetal and Neonatal Edition, vol. 83, no. 1, pp. F56F59, 2000.

[37] D. Askenazi, "Evaluation and management of critically ill children with acute kidney injury," Current Opinion in Pediatrics, vol. 23, no. 2, pp. 201-207, 2011.

[38] A. P. Lavery, J. K. Meinzen-Derr, E. Anderson et al., "Urinary NGAL in premature infants," Pediatric Research, vol. 64, no. 4, pp. 423-428, 2008.

[39] J. V. Bonventre, V. S. Vaidya, R. Schmouder, P. Feig, and F. Dieterle, "Next-generation biomarkers for detecting kidney toxicity," Nature Biotechnology, vol. 28, no. 5, pp. 436-440, 2010.

[40] J. L. Alge, N. Karakala, B. A. Neely et al., "Urinary angiotensinogen and risk of severe AKI," Clinical Journal of the American Society of Nephrology, vol. 8, no. 2, pp. 184-193, 2013.

[41] J. L. Alge, N. Karakala, B. A. Neely, M. G. Janech, J. C. Velez, and J. M. Arthur, "Urinary angiotensinogen predicts adverse outcomes among acute kidney injury patients in the intensive care unit," Critical Care, vol. 17, no. 2, article R69, 2013.

[42] J. L. Alge, N. Karakala, B. A. Neely et al., "Association of elevated urinary concentration of renin-angiotensin system components and severe AKI," Clinical Journal of the American Society of Nephrology, vol. 8, no. 12, pp. 2043-2052, 2013.

[43] D. J. Askenazi, A. Montesanti, H. Hunley et al., "Urine biomarkers predict acute kidney injury and mortality in very low birth weight infants," Journal of Pediatrics, vol. 159, no. 6, pp. 907.el912.el, 2011.

[44] C. D. Krawczeski, J. G. Woo, Y. Wang, M. R. Bennett, Q. Ma, and P. Devarajan, "Neutrophil gelatinase-associated lipocalin concentrations predict development of acute kidney injury in neonates and children after cardiopulmonary bypass," Journal of Pediatrics, vol. 158, no. 6, pp. 1009.e1-1015.el, 2011.

[45] Y. Li, C. Fu, X. Zhou et al., "Urine interleukin-18 and cystatin-C as biomarkers of acute kidney injury in critically ill neonates," Pediatric Nephrology, vol. 27, no. 5, pp. 851-860, 2012.

[46] K. Sarafidis, E. Tsepkentzi, E. Agakidou et al., "Serum and urine acute kidney injury biomarkers in asphyxiated neonates," Pediatric Nephrology, vol. 27, no. 9, pp. 1575-1582, 2012. 
[47] A. T. Elmas, Y. Tabel, and O. N. Elmas, "Serum cystatin C predicts acute kidney injury in preterm neonates with respiratory distress syndrome," Pediatric Nephrology, vol. 28, no. 3, pp. 477484, 2013.

[48] L. Cataldi, M. Mussap, L. Bertelli, N. Ruzzante, V. Fanos, and M. Plebani, "Cystatin C in healthy women at term pregnancy and in their infant newborns: relationship between maternal and neonatal serum levels and reference values," The American Journal of Perinatology, vol. 16, no. 6, pp. 287-295, 1999.

[49] A. P. Sharma, A. Kathiravelu, R. Nadarajah, A. Yasin, and G. Filler, "Body mass does not have a clinically relevant effect on cystatin C eGFR in children," Nephrology Dialysis Transplantation, vol. 24, no. 2, pp. 470-474, 2009.

[50] V. Y. Melnikov, S. Faubel, B. Siegmund, M. S. Lucia, D. Ljubanovic, and C. L. Edelstein, "Neutrophil-independent mechanisms of caspase-1- and IL-18-mediated ischemic acute tubular necrosis in mice," Journal of Clinical Investigation, vol. 110, no. 8, pp. 1083-1091, 2002.

[51] J. Mishra, M. A. Qing, A. Prada et al., "Identification of neutrophil gelatinase-associated lipocalin as a novel early urinary biomarker for ischemic renal injury," Journal of the American Society of Nephrology, vol. 14, no. 10, pp. 2534-2543, 2003.

[52] G. Wagener, G. Gubitosa, S. Wang, N. Borregaard, M. Kim, and H. T. Lee, "Urinary neutrophil gelatinase-associated lipocalin and acute kidney injury after cardiac surgery," The American Journal of Kidney Diseases, vol. 52, no. 3, pp. 425-433, 2008.

[53] A. Di Grande, C. Giuffrida, G. Carpinteri et al., "Neutrophil gelatinase-associated lipocalin: a novel biomarker for the early diagnosis of acute kidney injury in the emergency department," European Review for Medical and Pharmacological Sciences, vol. 13, no. 3, pp. 197-200, 2009.

[54] C. R. Parikh, P. Devarajan, M. Zappitelli et al., "Postoperative biomarkers predict acute kidney injury and poor outcomes after pediatric cardiac surgery," Journal of the American Society of Nephrology, vol. 22, no. 9, pp. 1737-1747, 2011.

[55] F. I. Fadel, A. M. Abdel Rahman, M. F. Mohamed et al., "Plasma neutrophil gelatinase-associated lipocalin as an early biomarker for prediction of acute kidney injury after cardio-pulmonary bypass in pediatric cardiac surgery," Archives of Medical Science, vol. 8, no. 2, pp. 250-255, 2012.

[56] Y. Tabel, A. Elmas, S. Ipek, A. Karadag, O. Elmas, and F. Ozyalin, "Urinary neutrophil gelatinase-associated lipocalin as an early biomarker for prediction of acute kidney injury in preterm infants," The American Journal of Perinatology, vol. 31, no. 2, pp. 167-174, 2014.

[57] C. D. Krawczeski, R. G. Vandevoorde, T. Kathman et al., "Serum cystatin $\mathrm{C}$ is an early predictive biomarker of acute kidney injury after pediatric cardiopulmonary bypass," Clinical Journal of the American Society of Nephrology, vol. 5, no. 9, pp. 1552-1557, 2010.

[58] R. C. Abdulkader, A. B. Liborio, and D. M. Malheiros, "Histological features of acute tubular necrosis in native kidneys and long-term renal function," Renal Failure, vol. 30, no. 7, pp. 667673, 2008.

[59] D. P. Basile, D. Donohoe, K. Roethe, and J. L. Osborn, "Renal ischemic injury results in permanent damage to peritubular capillaries and influences long-term function," The American Journal of Physiology-Renal Physiology, vol. 281, no. 5, pp. F887-F899, 2001.

[60] D. P. Basile, "Rarefaction of peritubular capillaries following ischemic acute renal failure: a potential factor predisposing to progressive nephropathy," Current Opinion in Nephrology and Hypertension, vol. 13, no. 1, pp. 1-7, 2004.

[61] S. G. Coca, S. Singanamala, and C. R. Parikh, "Chronic kidney disease after acute kidney injury: a systematic review and metaanalysis," Kidney International, vol. 81, no. 5, pp. 442-448, 2012.

[62] H. Wakaki, K. Ishikura, H. Hataya et al., "Henoch-Schönlein purpura nephritis with nephrotic state in children: predictors of poor outcomes," Pediatric Nephrology, vol. 26, no. 6, pp. 921925, 2011.

[63] A. X. Garg, R. S. Suri, N. Barrowman et al., "Long-term renal prognosis of diarrhea-associated hemolytic uremic syndrome: a systematic review, meta-analysis, and meta-regression," The Journal of the American Medical Association, vol. 290, no. 10, pp. 1360-1370, 2003. 


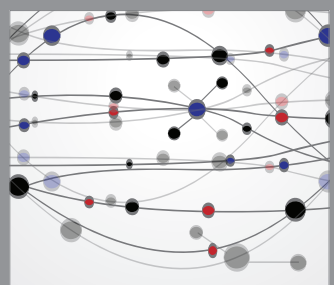

The Scientific World Journal
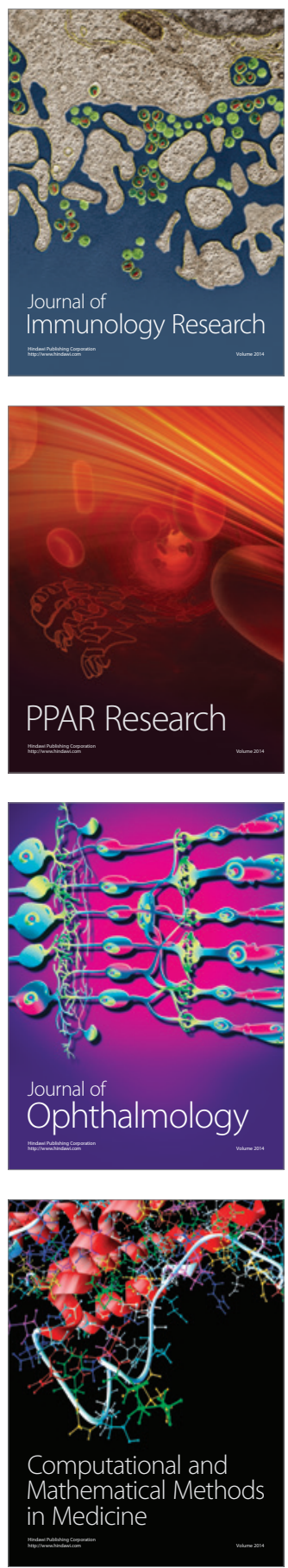

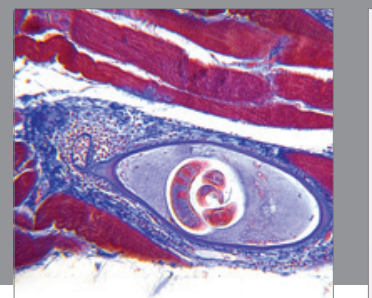

Gastroenterology

Research and Practice
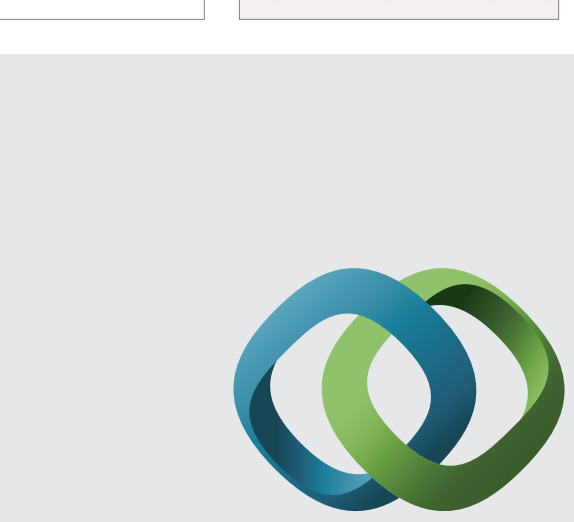

\section{Hindawi}

Submit your manuscripts at

http://www.hindawi.com
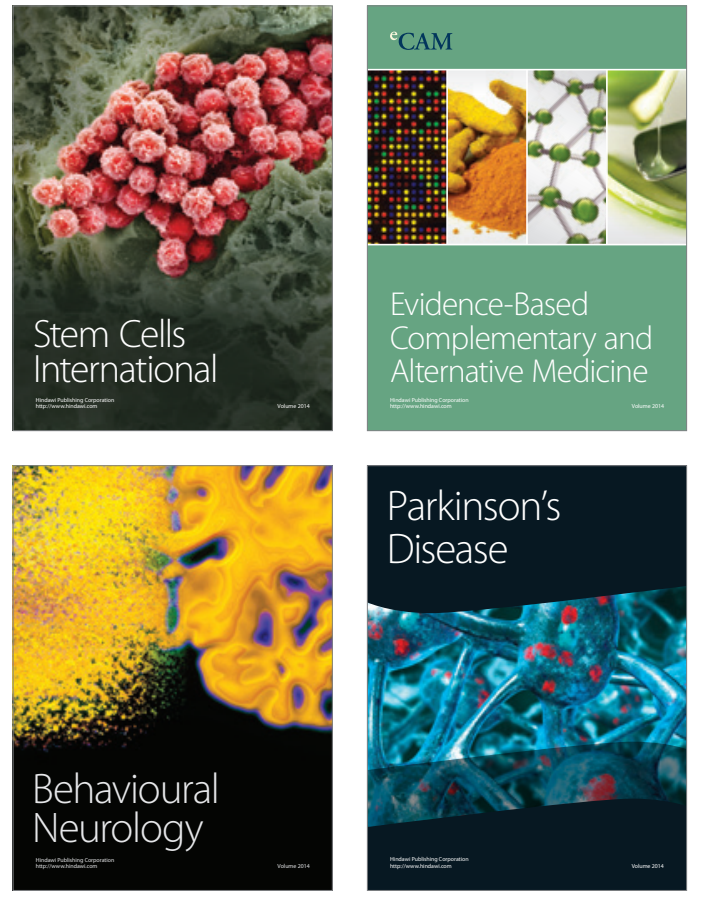
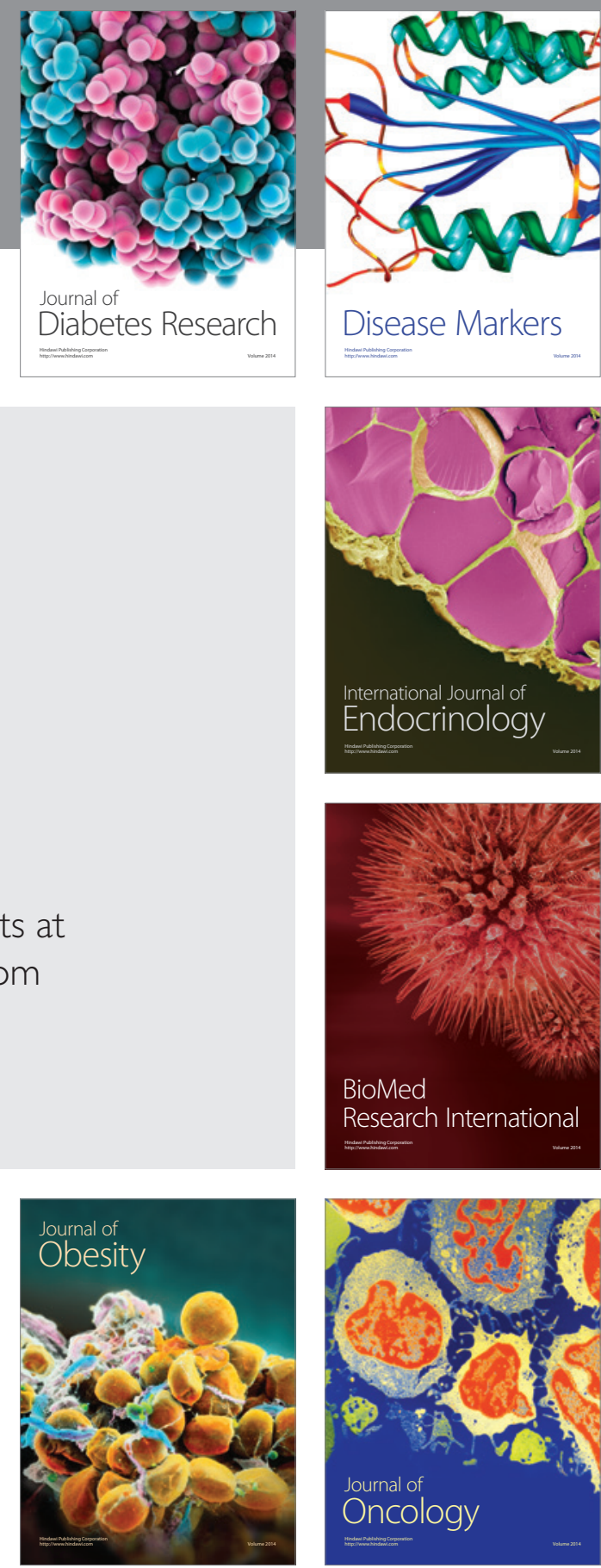

Disease Markers
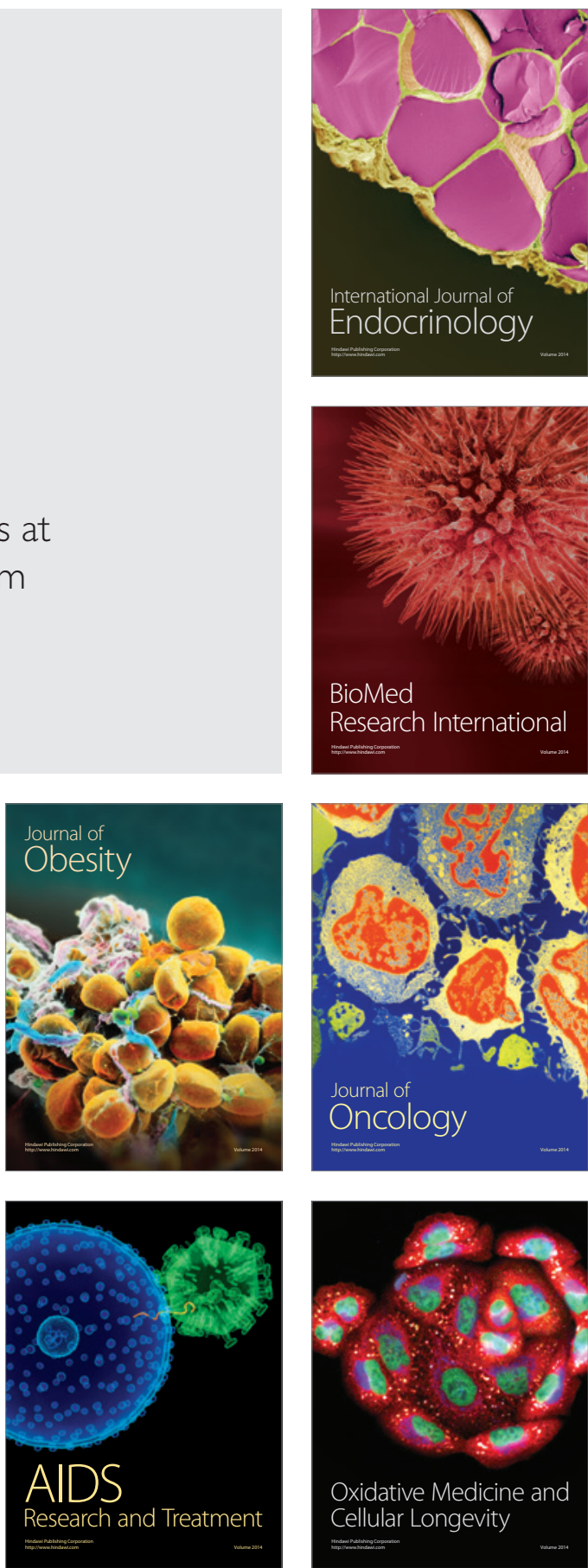